\title{
Static behaviour of a two-tiered Dou-Gong system reinforced by super-elastic alloy
}

Wenjun Xie MEng, PhD

Former PhD student, Department of Architecture and Civil Engineering, University of Bath, Bath, UK

Tsung-Hsien Wang PhD

Lecturer, Sheffield School of Architecture, University of Sheffield, Sheffield, UK

\author{
Wen-Shao Chang PhD \\ Senior Lecturer, Sheffield School of Architecture, University of Sheffield, \\ Sheffield, UK (corresponding author: w.chang@sheffield.ac.uk) \\ (Orcid:0000-0002-2218-001X)
}

The Dou-Gong system in Asian timber structures plays an important role in resisting seismic action. Traditional carpentry in Asia uses timber pegs to connect components, which enables relative movement between components and hence provides friction to dissipate energy in an earthquake. This method, however, has some shortcomings, such as inadequate stiffness to resist a large lateral force, and, therefore, the structures tend to exhibit permanent deformation after earthquakes. This study proposes a new technique by using super-elastic alloy bars to replace conventional wooden peg connections to enhance the seismic performance of the structures. Static pushover experiments were conducted on full-scale two-tiered Dou-Gong systems, and high-strength steel and conventional wooden pegs were used as benchmarks. The ultimate stiffness of the Dou-Gong system has shown an increase when both high-strength steel and super-elastic alloy bars were used, but only super-elastic alloy can provide a consistently high damping ratio. This technique also involves pre-strain of the super-elastic alloy, and the outcomes of this series of experiments have shown that pre-strain of the super-elastic alloy can significantly increase the damping ratio in the structure, and, hence, more energy is dissipated. The results of this paper can be used in projects of timber structures using the Dou-Gong system.

\section{Notation}

$A_{\mathrm{e}} \quad$ maximum elastic strain energy in one loading cycle

$A_{\mathrm{h}} \quad$ dissipated energy in one loading cycle

$A_{\mathrm{s}}, A_{\mathrm{f}}$ start and finish transformation temperature points between austenite phases

$a \quad$ width of base dou

E modulus of elasticity

$f \quad$ strength

g gravity

$H \quad$ height of the Dou-Gong set

$L \quad$ length of the top beam

$M \quad$ restoring moment

$M_{\mathrm{s}}, M_{\mathrm{f}}$ start and finish transformation temperature points between martensite phases

$P \quad$ lateral force imposed on the structure

$W \quad$ weight on top of the structure

$\zeta \quad$ equivalent damping ratios

$\theta$ rotational angle

\section{Introduction}

Existing oriental timber buildings which have a long history are often considered the cultural heritage of a country. A large proportion of these buildings are situated in the seismic belts in East Asia; thus, there is a critical need for conservation against earthquakes and other forms of natural disaster. These timber buildings have diverse connection systems, such as dovetail connections (Chang and Hsu, 2005) and Dou-Gong systems. The anti-seismic performance of historic timber buildings has been extensively studied over the past 20 years (Chang, 2005; Chang and Hsu, 2007; Chang et al., 2006, 2009; Fang et al., 2001a, 2001b; Fujita et al., 2004; Suzuki and Maeno, 2006; Xie et al., 2018; Xue et al., 2015; Yeo et al., 2018; Yu et al., 2008), and it has been recognised that Dou-Gong systems in historic timber buildings play an important role in resisting seismic action. DouGong systems are located at the top of columns to support upper structures and transmit the weight of both the structures and the roof to the columns and the foundations. The fundamental elements of a Dou-Gong system are the Dou (斗), Gong (拱) and Ang (昂), as shown in Figure 1. The Dou is a rectangular timber element with a cross-groove at its upper side. Gong and Ang are timber elements placed onto the cross-groove of the Dou perpendicular and parallel to the beams, respectively. A Dou is connected to the lower elements by a wooden peg (Figure 2).

Both static and dynamic experiments and analysis have been conducted by many researchers, who have confirmed the non-linear stiffness of Dou-Gong (Fujita et al., 2000, 2008; Hwang et al., 2008; Suzuki and Maeno, 2006; Tsuwa et al., 2008; Yeo et al., 2016a, 2016b). The rotation of the base Dou often experiences major horizontal deformation in the region of initial stiffness. Sliding has been observed when the horizontal load exceeds the frictional capacity between the elements, and this has resulted in the lower second stiffness. The Dou-Gong system dissipates most of the energy through the sliding and movements between each element.

Although the Dou-Gong system has a self-centring nature and can undergo large deformations, many historical buildings have been seriously damaged or have collapsed in the event of an earthquake due to the low strength and stiffness of the Dou-Gong system. For example, during the 1999 Chi-Chi earthquake in Taiwan, 42\% of 
Engineering History and Heritage

Volume 172 Issue EH4
Static behaviour of a two-tiered DouGong system reinforced by super-elastic alloy Xie, Wang and Chang

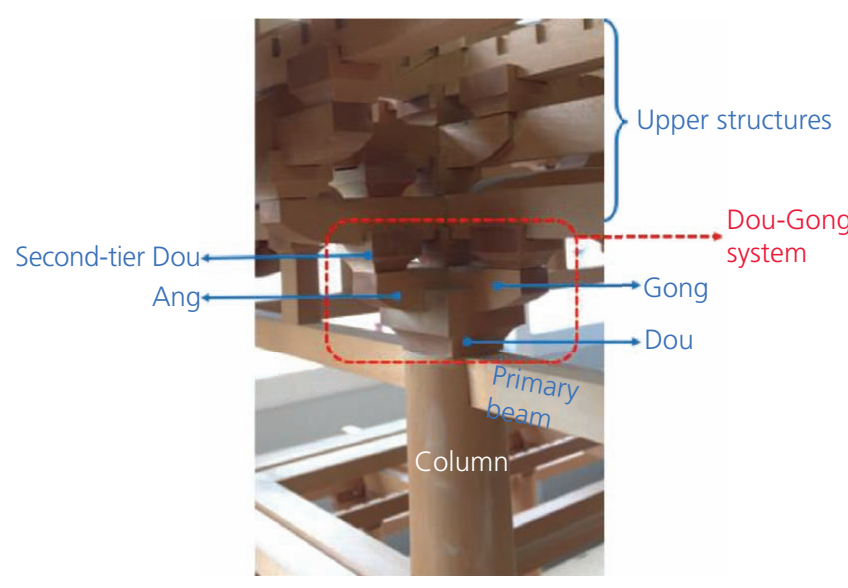

Figure 1. Location of the Dou-Gong system and its formation (Xie et al., 2018)

traditional timber structures were seriously damaged and $48 \%$ collapsed, whereas only $10 \%$ of other buildings were damaged (Chang, 2005). Enhancing the seismic performance of the Dou-Gong system is therefore the primary task that needs to be focused on but has yet to be started in earnest.

Two fundamental advantages that the Dou-Gong system provides to ensure good anti-seismic performance are its recentring capability and energy dissipation capacity. The recentring capability is driven by the recentring force, which pulls the oblique structure back to its original position. The weakest point of the Dou-Gong system is the conventional wooden peg, which, after an earthquake, either is pulled out from the hole or exhibits permanent deformation. A simple technique has been developed whereby metal bars are used to replace the conventional wooden peg connections to enhance the seismic performance of the base Dou. This is achieved by maintaining the base Dou's original recentring capability and increasing both its energy dissipation capacity and its ultimate strength (Xie et al., 2018).

This paper reports pushover experiments conducted on Dou-Gong systems with two tiers. Tests were conducted with conventional wooden peg connections and two metal connections (highstrength steel and super-elastic alloy).

\section{Experimental method}

A full-scale replica of a two-tiered Dou-Gong system, which duplicates a historical building in Sichuan Province in China, was made of glued laminated (glulam) timber. The conventional connections of Dou and the lower structure were wooden pegs. The tests involved using high-strength steel and a super-elastic alloy to replace the wooden pegs to improve the seismic performance of the Dou-Gong system. Pushover tests were then conducted where the lateral loads were applied using a hydraulic jack. The displacements and rotations of components of the DouGong system were measured by 18 linear variable differential

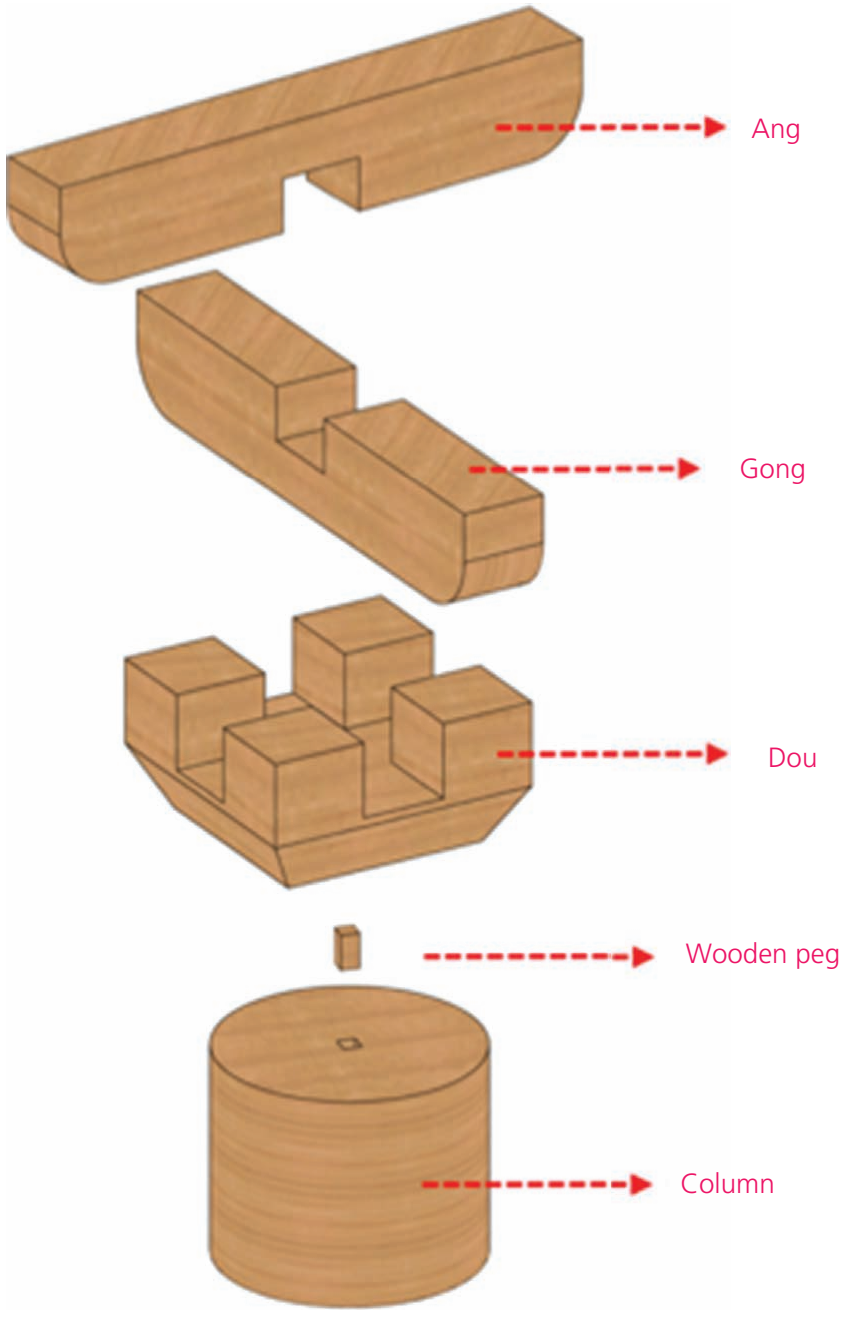

Figure 2. Three-dimensional drawing of elements in the DouGong system

transformers (LVDTs). Moment-rotation curves were then obtained to evaluate the seismic performance.

\subsection{Materials}

The material used to make the Dou-Gong system was glulam GL28h, and its mechanical properties are listed in Table 1. Apart from the Gong and Ang, which connect by interlocking, the conventional wooden pegs that connect Dou and the lower

Table 1. Mechanical properties of glulam GL28h

$\begin{array}{lc}\text { Mean modulus of elasticity }\left(E_{0, \text { mean }}\right) & 12600 \mathrm{~N} / \mathrm{mm}^{2} \\ \text { Mean modulus of elasticity perpendicular to } & 420 \mathrm{~N} / \mathrm{mm}^{2} \\ \text { grain }\left(E_{90, \text { mean }}\right) & \\ \text { Bending strength }\left(f_{\mathrm{m}, \mathrm{k}}\right) & 28 \mathrm{~N} / \mathrm{mm}^{2} \\ \text { Tension strength }\left(f_{\mathrm{t}, 0, \mathrm{k}}\right) & 19.5 \mathrm{~N} / \mathrm{mm}^{2} \\ \text { Compression strength }\left(f_{\mathrm{c}, 0, \mathrm{k}}\right) & 26.5 \mathrm{~N} / \mathrm{mm}^{2} \\ \text { Compression strength perpendicular to } & 3 \cdot 0 \mathrm{~N} / \mathrm{mm}^{2} \\ \text { grain }\left(f_{\mathrm{c}, 90, \mathrm{k}}\right) & \end{array}$


structure were also made using GL28h. The reason for the use of glulam was due to the limitation of accessing large-sectioned sawn timber to make the specimens.

Two materials, high-strength steel and super-elastic alloy bars (as shown in Figure 3), were used to replace the wooden pegs. The original diameter of the bars was $12 \mathrm{~mm}$. The middle part of the bar was machined down to $6 \mathrm{~mm}$ to lower the pre-strain load on the timber, and threads of M8 and M12 were located at each end. The length of the reduced section was $105 \mathrm{~mm}$ for the base Dou connection and $60 \mathrm{~mm}$ for upper Dou connections.

The super-elastic alloy is a smart material known as a shapememory alloy because its shape-memory effect has been widely used in many different fields, including civil structures, the

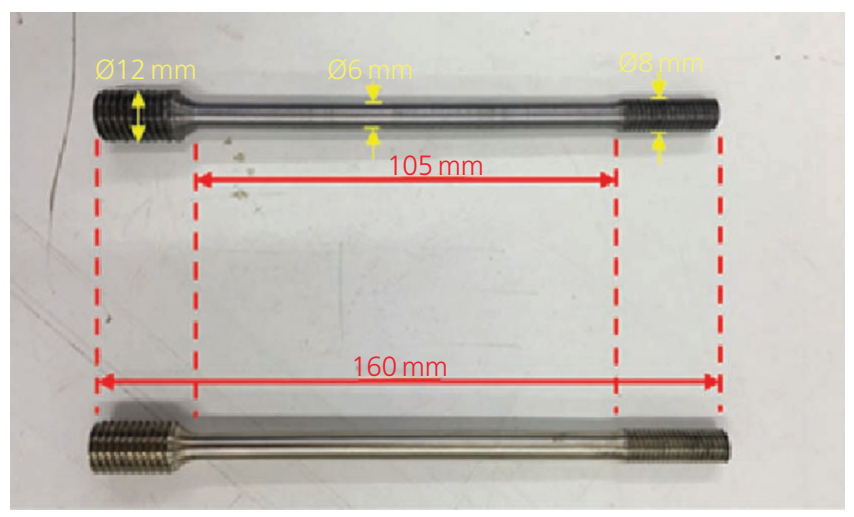

Figure 3. Bar connection for the base Dou with dimensions. Upper: high-strength steel; lower: super-elastic alloy (Xie et al., 2018)

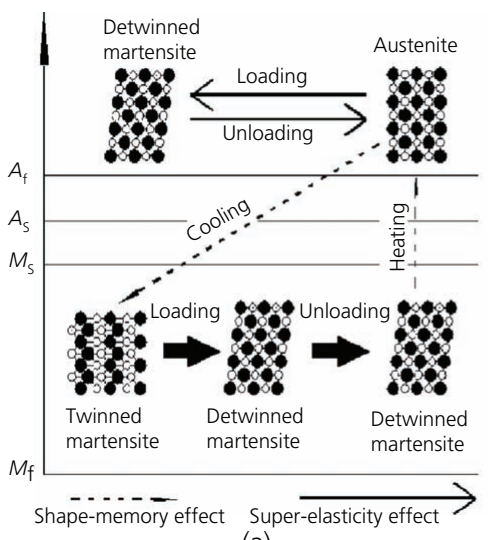

(a)

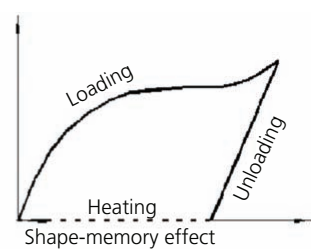

(b)

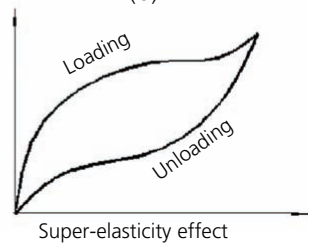

(c)
Figure 4. The different phases of the super-elastic alloy at different temperatures and their relationship with the shapememory and super-elasticity effects (Chang and Araki, 2016): (a) transformation between shape-memory effect and super-elastic effect; (b) behaviour of shape-memory effect; (c) behaviour of super-elastic effect automotive industry, aircraft and medicine. The materials used in this research have a super-elasticity effect. The nature of the materials and their two different effects are schematised in Figure 4 (Chang and Araki, 2016). The material has two crystal structures, austenite and martensite, which can be transformed to each other by changing the temperature of the material and altering the external stress. $M_{\mathrm{s}}, M_{\mathrm{f}}, A_{\mathrm{s}}$ and $A_{\mathrm{f}}$ denote the start and finish transformation temperature points between martensite and austenite phases and are set during the manufacture of the materials. The super-elastic alloy used in this research was provided by Furukawa Techno Material Co., Ltd, Japan, and it has a transformation temperature, $A_{\mathrm{f}}$, of $-39^{\circ} \mathrm{C}$, which is much lower than the ambient temperature of most regions in the world, particularly within the area in which the historic timber buildings are distributed. This material therefore has a super-elasticity effect that can invoke phase transformations by changing the external stress.

A pre-strain (Figure 5) can be applied to the super-elastic alloy bar by applying an axial tensile force onto the bar. This will change the initial crystal structure of the connection bar to detwinned martensite and theoretically omit the initial elastic stage and thus dissipate energy more quickly.

The high-strength steel bar was tested axially and yielded an ultimate strength of $720 \mathrm{MPa}$, much higher than that of the superelastic alloy bar. However, the high-strength steel bar fractured at $3.6 \%$ strain. There was negligible residual strain of the superelastic alloy bar after tensile tests up to $7 \%$ strain. Figure 6 compares the stress-strain curves of high-strength steel bar and the super-elastic ally bar. The chemical composites of the superelastic alloy used in this research were copper (81.84 wt\%), aluminium $(7.43 \mathrm{wt} \%)$ and manganese $(10.74 \mathrm{wt} \%)$, which were measured using a scanning electron microscope.

\subsection{Dou-Gong specimen and structure set-up}

The two-tiered Dou-Gong system consisted of 11 individual components, including the timber block that represents the top of a column. The lower layer comprised a base Dou, one Gong and one

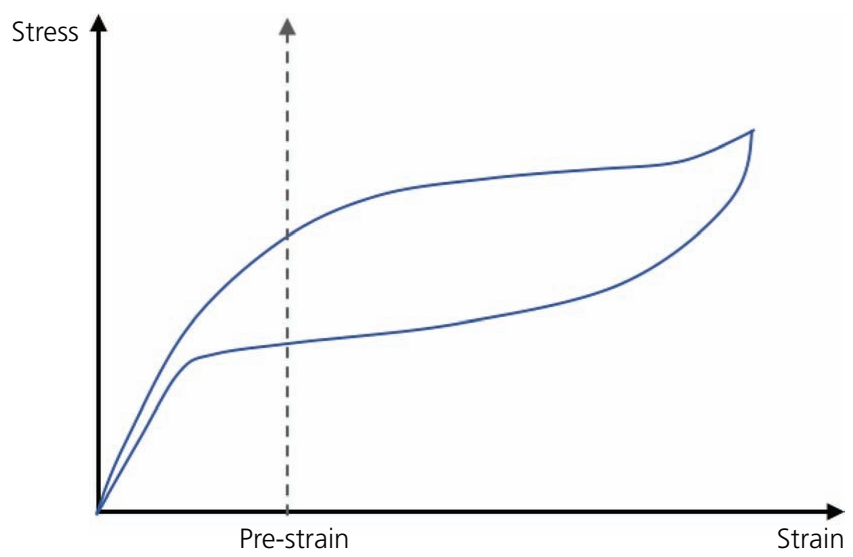

Figure 5. Schematic diagram of pre-strain on super-elastic alloy 
Static behaviour of a two-tiered DouGong system reinforced by super-elastic alloy Xie, Wang and Chang

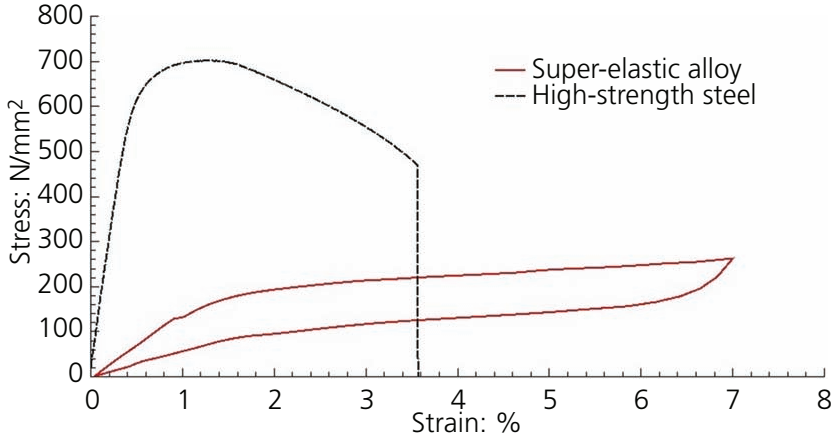

Figure 6. Stress-strain curves of metal bars (Xie et al., 2018)

Ang. The upper layer comprised four small Dous, 3 Gongs and one Ang. Each Dou was connected to the lower structure by a wooden peg. There are two types of wooden peg connections, dovetail and flat cut. The pull-out force is independent of the dead load when the dovetail connection is used but changes along with the dead load when a flat-cut connection is used. In this research, flat-cut wooden peg connections were applied. The dimensions were $28 \times 28 \times$ $56 \mathrm{~mm}$ for the base Dou connection and $26 \times 26 \times 52 \mathrm{~mm}$ for the upper layer Dou connections.

The timber block that represents the top of the column was fixed to the strong floor by two $24 \mathrm{~mm}$ threaded bolts. Two angle plates were also fixed to the strong floor to prevent the timber block from sliding.

The two-tiered Dou-Gong system was placed on top of the block in sequence, as shown in Figure 7. The Gong and Ang were fitted in the grooves of the Dou and bonded together. Five Dous were connected to the lower structures by wooden pegs or metal bars. Cubic holes with a width of $28 \mathrm{~mm}$ were chiselled out for the wooden pegs in both the bottom of the base Dou and the top of the timber block, while $26 \mathrm{~mm}$ wide holes were chiselled out in the bottom of four upper Dou and the top of the corresponding elements.

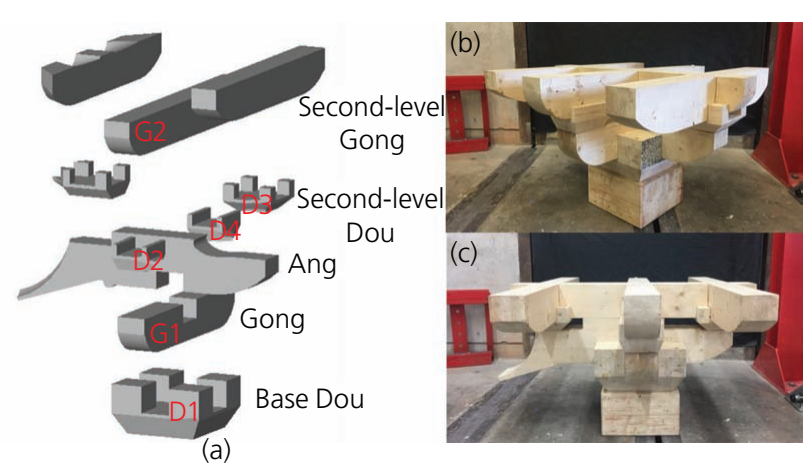

Figure 7. (a) Three-dimensional exploded-view drawing of DouGong; (b, c) Dou-Gong set-up without dead loads
As Figure 8 shows, a simple system was developed for the metal bar connections. Thread inserts $(12 \mathrm{~mm}$ ) (Figure 8(a)) were fixed into the timber block, first-level Gong and Ang using epoxy resin. The metal bar was placed first and inserted through the centre of the Gong along a pre-drilled vertical hole. A $100 \mathrm{~mm}$ square steel plate and $50 \mathrm{~mm}$ dia. washers were then embedded in the top surfaces of the base Dou and upper-level Dou, respectively, to prevent damage to the timber caused by axial loads from the bar. A ball joint was then placed on top to remove the rotational restraint and provide a pin-joint to the connection system. The top end of the connection system was fixed by a nut, which in some cases gives the pre-strain load to the super-elastic bar. This connection system is shown in detail in Figure 8(c).

Eight LVDTs (1-8) were attached to the first-level Gong and Ang to measure the sliding displacements and rotations of four upperlevel Dous. Two sets of four LVDTs (9-16) were placed vertically to measure the total rotations and base Dou rotations, respectively. The radian of each rotation was calculated from the differences in the measurement of LVDTs on the left and right sides, as shown in Figure 9. Two horizontal LVDTs (17 and 18) measured the horizontal sliding displacement of both the base Dou and the
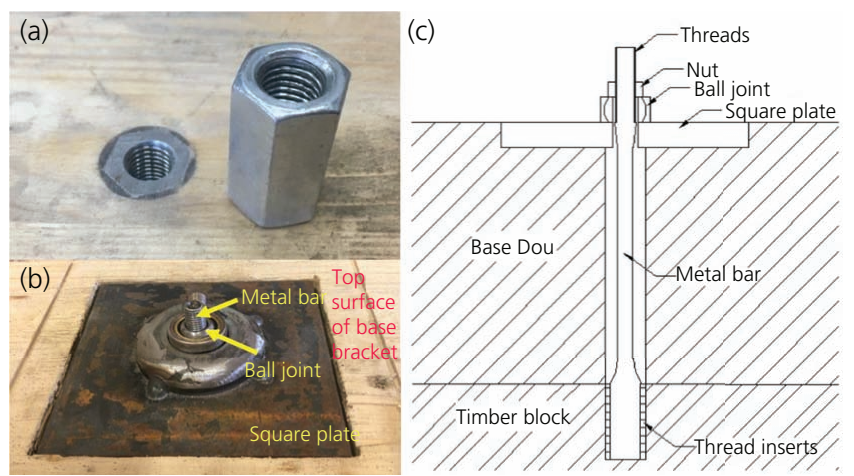

Figure 8. (a) Thread insert (12 mm); (b) square plate and ball joint; (c) details of metal bar connection (Xie et al., 2018)

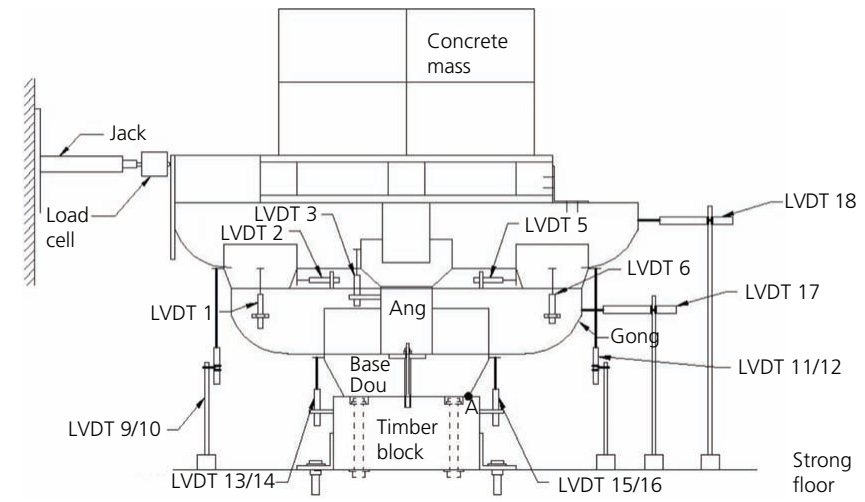

Figure 9. Loading apparatus and instrumentation (Xie et al., 2018) 
Table 2. Test protocol

\begin{tabular}{|llcc} 
Test number & $\begin{array}{c}\text { Material for } \\
\text { connection }\end{array}$ & $\begin{array}{c}\text { Weights on top: } \\
\mathbf{k g}\end{array}$ & Pre-strain \\
\hline 1 & Wooden peg & 400 & N/A \\
2 & Wooden peg & 700 & N/A \\
3 & Wooden peg & 1000 & N/A \\
4 & Steel bar & 400 & N/A \\
5 & Steel bar & 700 & N/A \\
6 & Steel bar & 1000 & N/A \\
7 & SEA bar & 400 & None \\
8 & SEA bar & 700 & None \\
9 & SEA bar & 1000 & None \\
10 & SEA bar & 400 & $1 \%$ \\
11 & SEA bar & 700 & $1 \%$ \\
12 & SEA bar & 1000 & $1 \%$ \\
13 & SEA bar & 400 & $3 \%$ \\
14 & SEA bar & 700 & $3 \%$ \\
15 & SEA bar & 1000 & $3 \%$ \\
\hline
\end{tabular}

N/A, not applicable; SEA, super-elastic alloy

entire structure. A pallet was fixed on top of the Dou-Gong to house the concrete blocks and simulate the vertical load exerted on the structure. The lateral loads were applied by a hydraulic jack fixed onto the wall. The vertical distance from the loading point to the bottom level of the base Dou was $700 \mathrm{~mm}$. The setup details for this structure are shown in Figure 9.

\subsection{Test programme}

For historic buildings, the weight of the roof plays a very important role in the structure and can often vary. To simulate this, 400, 700 and $1000 \mathrm{~kg}$ weights were applied to the top of the structure to explore how the weight of the roof changes the behaviour of the structure.

As listed in the test protocol (Table 2), three different materials connecting the Dou and the lower elements under three weight levels were applied. One loading cycle was defined as the trajectory of the Dou-Gong system that rotates to a certain point with a prescribed radian and recovers to its original position. The three prescribed radians were 0.05, 0.06 and 0.07, and the DouGong system loaded three cycles for each radian. Thus, there were nine loading cycles in total for each test.

As has been explained in the discussion on the benefit of the prestrain, the super-elastic alloy bars were also pre-strained to 1 and $3 \%$ strain levels using the nut of the connection system. The pre-strained connection conditions were tested only at a weight of $1000 \mathrm{~kg}$.

\section{Results and discussions}

\subsection{Dou-Gong set with conventional wooden peg connections}

The results of the Dou-Gong set with conventional wooden peg connections can be illustrated using moment-rotation curves. The curves in Figure 10 represent three stages of stiffness under a

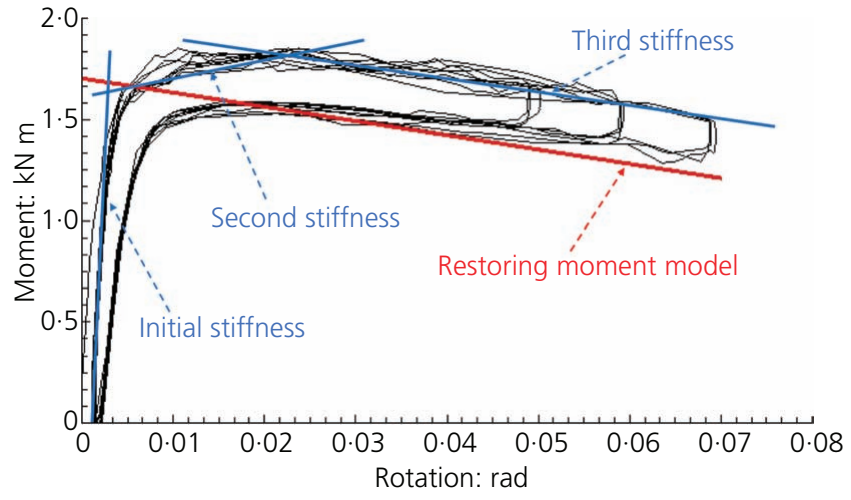

Figure 10. Hysteresis loops of the Dou-Gong set with wooden peg connections at a weight of $1000 \mathrm{~kg}$

$1000 \mathrm{~kg}$ roof weight. The first is a initial elasticity stage, with a stiffness of $900 \mathrm{kN} \mathrm{m} / \mathrm{rad}$. During the second, plastic stage, the wooden peg of the base Dou starts to pull out from the chiselled hole. The structure then begins to tip over, and the lateral load is then decreased during the third stage of stiffness, the limit stage. Because the Dou-Gong has a good recentring capability, the structure then rotated back to its original position without significant residual displacement after the lateral loads had been removed.

The restoring moment of the Dou-Gong set can be calculated using the equation

1. $M=\frac{W \times \boldsymbol{g} \times \cos \theta}{2000 L}\left(L^{2}-2 a L-2 L H \times \tan \theta\right)$

The parameters are illustrated in Figure 11.

The second level of the structure was assumed to be a rigid frame as there were four Dous connected to the lower structure, which restrained the movement of the upper-level structure. The restoring moment model at a weight of $1000 \mathrm{~kg}$ is shown in Figure 10 . The stiffness was virtually the same for both the model

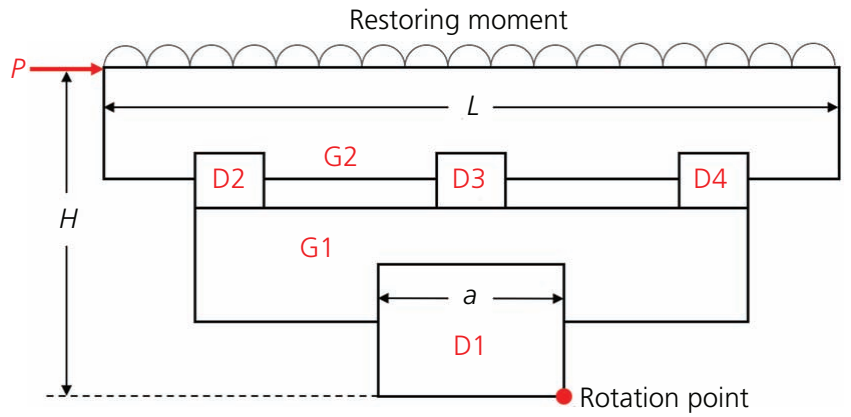

Figure 11. Simplified model of the structure and loadings 
Static behaviour of a two-tiered DouGong system reinforced by super-elastic alloy Xie, Wang and Chang

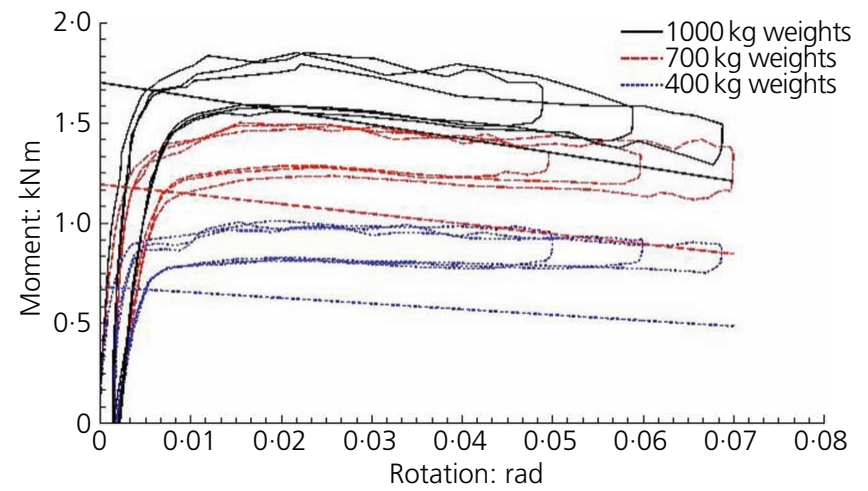

Figure 12. Hysteresis loops of the Dou-Gong set with wooden peg connections under different weights

and the test results. The difference in level occurs because, in a practical situation, the upper-level structure gives a constant moment to the entire Dou-Gong set.

Only the hysteresis loops in the first loading cycle with the same rotation angle are shown in Figure 12 because there was negligible change at a weight of $1000 \mathrm{~kg}$ (Figure 10). Although the increased weight on the top of the structure will increase the horizontal resistance of the Dou-Gong set, it will ultimately result in a lower resistance once the Dou-Gong system reaches the displacement where the P-delta effect needs to be considered. This is shown clearly in Figure 12 when the weight increased to $1000 \mathrm{~kg}$. Therefore, a heavier roof means that there is a higher risk of tipping for a historical timber structure with conventional wooden peg connections in the event of an earthquake.

\subsection{Dou-Gong set with metal bar connections}

In this study, two metallic materials, high-strength steel and superelastic alloy, were substituted for the wooden pegs. The vertical loads and the loading schemes remained the same.

The Dou-Gong set with high-strength steel bar connections retained a good self-centring capability. It recovered to its original position after the lateral loads had been removed, even when the steel bars had yielded or fractured. The area within the hysteresis loops of the first loading cycle was much larger than in the other two loading cycles (Figure 13). This demonstrated that the Dou-Gong set with high-strength steel bar connections dissipated a large amount of energy in the first loading cycle and exhibited a substantial decrease in the next two loading cycles under the same rotation angle. This is because the steel bar entered its plastic stage and showed permanent deformation during the first loading cycle. With the vertical load, there is no significant change in the ultimate strength of the Dou-Gong set with high-strength steel bar connections.

The super-elastic alloy bar connections give the Dou-Gong set a lower ultimate strength than the high-strength steel bar connections; however, this is still much higher than that for

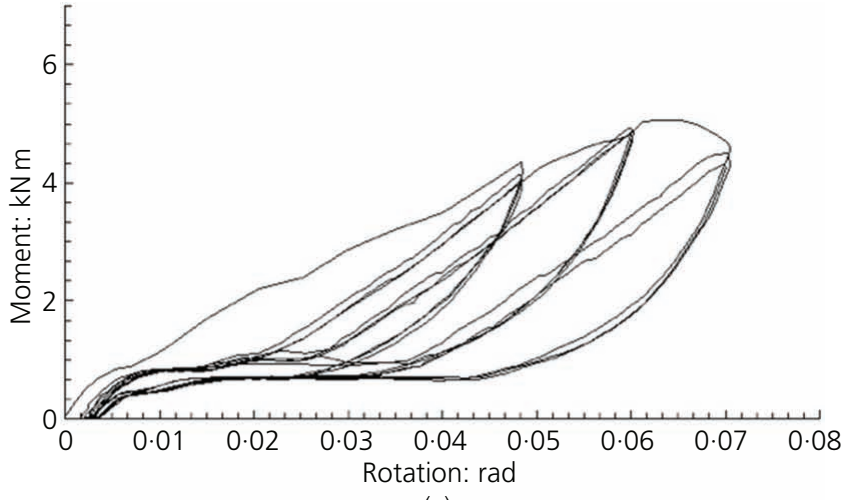

(a)

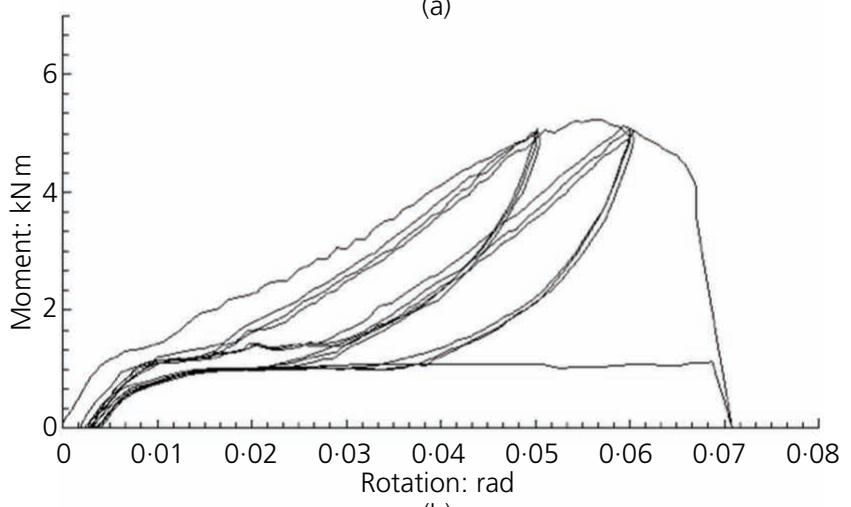

(b)

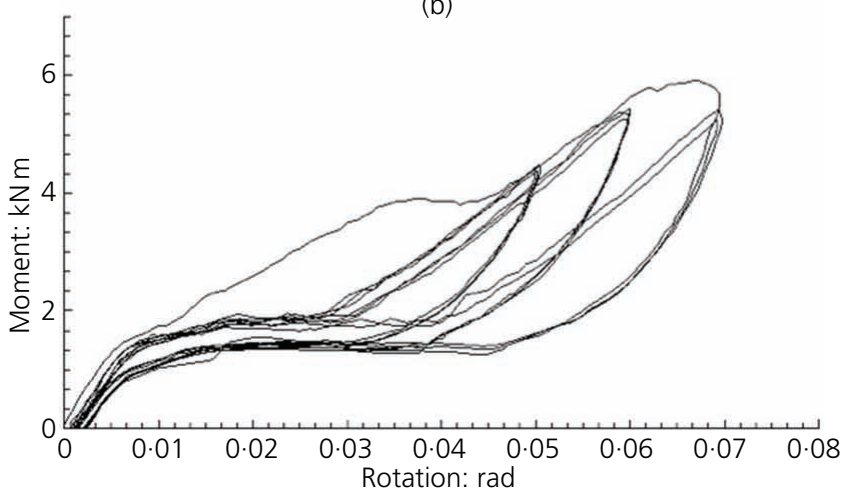

(c)

Figure 13. Hysteresis loops of the Dou-Gong set with highstrength steel bar connections: (a) $400 \mathrm{~kg}$ weight; (b) $700 \mathrm{~kg}$ weight; (c) $1000 \mathrm{~kg}$ weight

conventional wooden pegs. The Dou-Gong set experienced four stages of stiffness, as shown in Figure 14. The first two stages relate to the stiffness of the Dou-Gong itself, while the third and fourth stages come from the super-elastic alloy bars. The shapes of the hysteresis loops under the same rotation angle remain almost the same due to the super-elasticity of the super-elastic alloy bars. The ultimate strength of the Dou-Gong set with superelastic alloy bar connections increases significantly with the weight on top (as illustrated in Figure 15). A heavier roof will therefore give higher ultimate strength to the Dou-Gong set. The stiffness of the Dou-Gong does not vary with the weight of the roof. 
Static behaviour of a two-tiered Dou-

Gong system reinforced by super-elastic

alloy

Xie, Wang and Chang

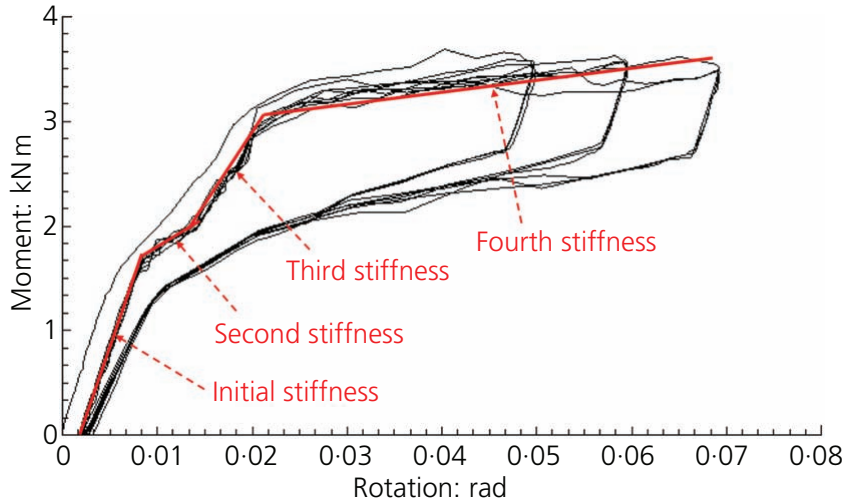

Figure 14. Hysteresis loops of the Dou-Gong set with superelastic alloy bar connections at a weight of $1000 \mathrm{~kg}$

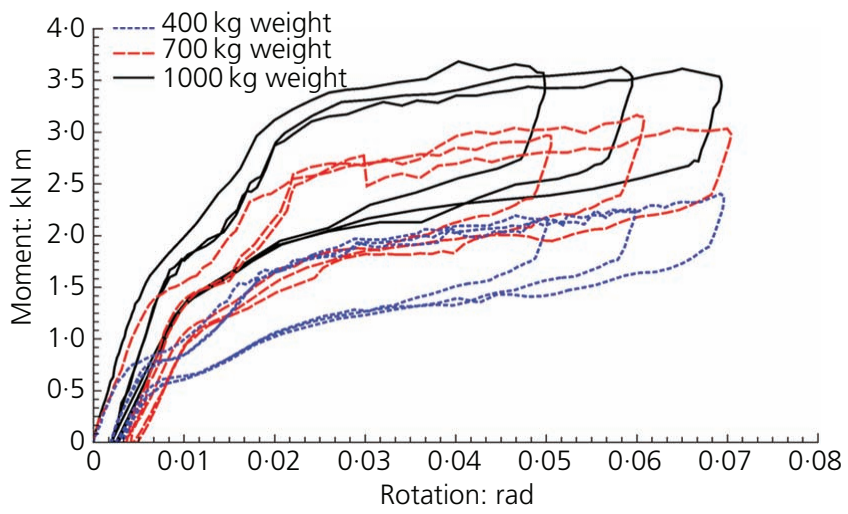

Figure 15. Hysteresis loops of the first cycle of each rotation step for the Dou-Gong set with super-elastic alloy bar connections

As Figure 16 shows, the second stiffness of the Dou-Gong with high-strength steel bar connections matched the stiffness of the Dou-Gong with conventional wooden peg connections. The highstrength steel bars did not exert any effort on the structure at this stage as the material experienced permanent deformation after the first loading cycle and must go through the low-stiffness stage, which is almost zero, from the second loading cycle (Figure 17). However, there was no noticeable change in the first and subsequent loading cycles when using the super-elastic alloy bar.

The equivalent damping ratios $(\zeta)$ for each loading case can be calculated using the equation (Priestley, 1996)

2. $\zeta=\frac{A_{\mathrm{h}}}{4 \pi \times A_{\mathrm{e}}}$

The Dou-Gong with high-strength steel bar connections gave equivalent damping ratios ranging from 5 to $10 \%$ in the first loading cycle, which reduced to $4-6 \%$ in the second and third

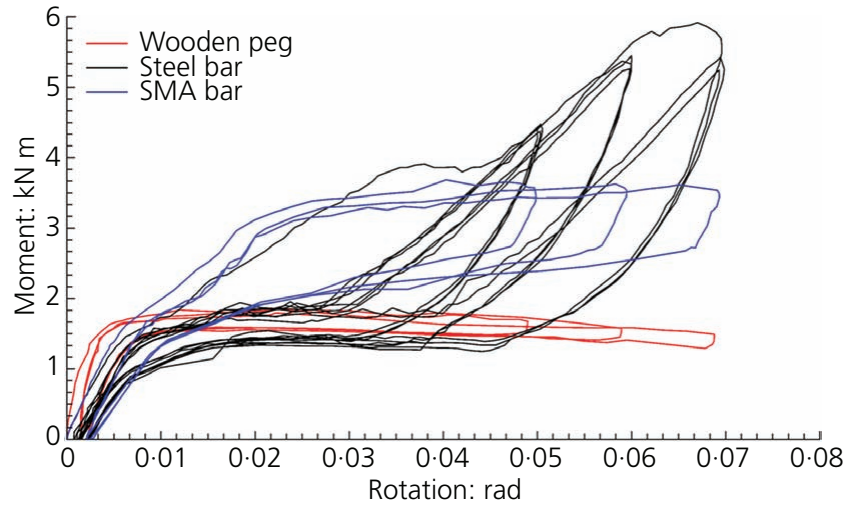

Figure 16. Comparison of three different connection materials at a weight of $1000 \mathrm{~kg}$. SMA, shape memory alloy

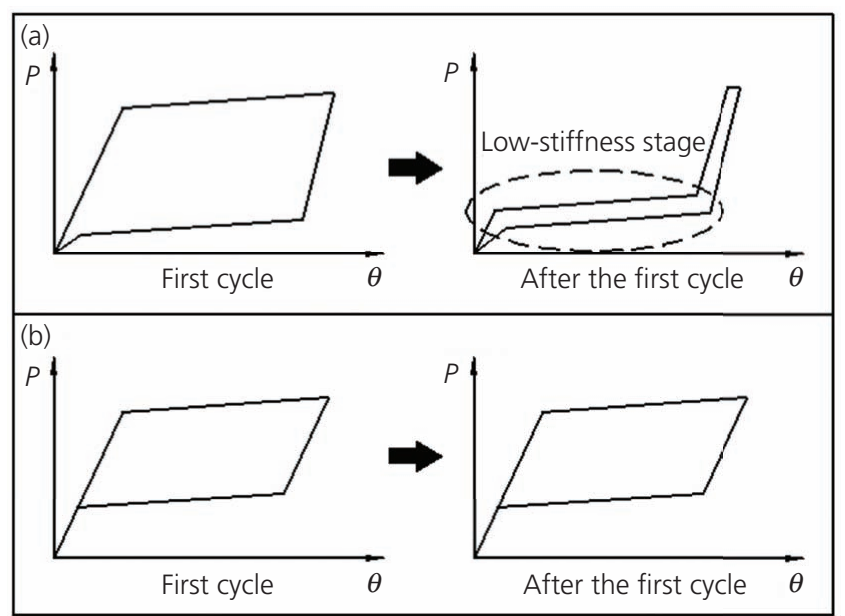

Figure 17. Schematic illustrations of the first two loading cycles of the Dou-Gong connected by (a) high-strength steel bars and (b) super-elastic alloy bars (Xie et al., 2018)

cycles. The super-elastic alloy gave equivalent damping ratios between 7 and $10 \%$ with a slight decrease in the second loading cycle (but still higher than 7\%), which remained the same in the third loading cycle. These data are presented in Figure 18, and the condition for each test is shown in Table 2. It is possible that, when using a high-strength steel bar, the equivalent damping ratio rises when the rotation angle increases. However, the steel will be fractured easily as it already has a permanent deformation, as shown in test 5 . There was no indication that the equivalent damping ratios changed with the rotation angle of the Dou-Gong when super-elastic alloy bar connections were used.

An earthquake always gives the structure more than one loading cycle, and there are several small aftershocks that structures need to overcome. A super-elastic alloy is therefore more suitable for seismic applications than high-strength steel because the latter 
Static behaviour of a two-tiered DouGong system reinforced by super-elastic alloy Xie, Wang and Chang

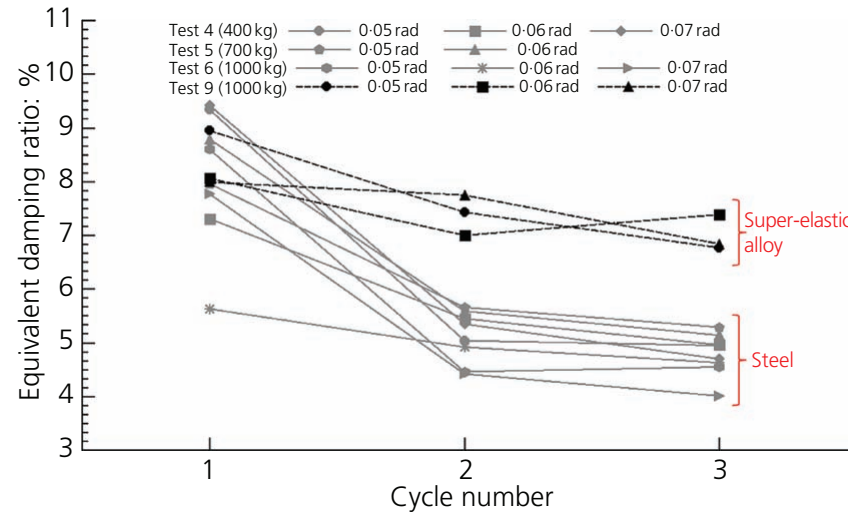

Figure 18. Change in equivalent damping ratios with loading cycle

will be damaged during a major earthquake and can provide neither sufficient stiffness nor good damping for the structure when it is subjected to small aftershocks.

\subsection{Effects of pre-strained super-elastic alloy}

The material tests and single Dou tests all show that the pre-strain of the super-elastic alloy could provide a better damping ratio and dissipate more energy. In this research, pre-strain levels of 1 and $3 \%$ were also applied to the super-elastic alloy bar connections.

The equivalent damping ratio of 'no-pre-strain' loading cases (tests 7-9) already showed a high equivalent damping ratio ranging from 7 to $9 \%$ (Figure 19). Figure 20 also shows that nopre-strain loading cases gave a higher equivalent damping ratio than the pre-strain loading cases. However, the hysteresis loops show that the $3 \%$ pre-strain loading cases dissipated more energy and had higher stiffness than both no-pre-strain and $1 \%$ pre-strain cases. The no-pre-strain loading cases gave a high equivalent damping ratio under rotations of more than $0.05 \mathrm{rad}$. They reached the super-elastic stage, and the material then showed the super-elasticity effect until the Dou-Gong set rotated to $0.02 \mathrm{rad}$. The Dou-Gong set retains its original stiffness and the elastic

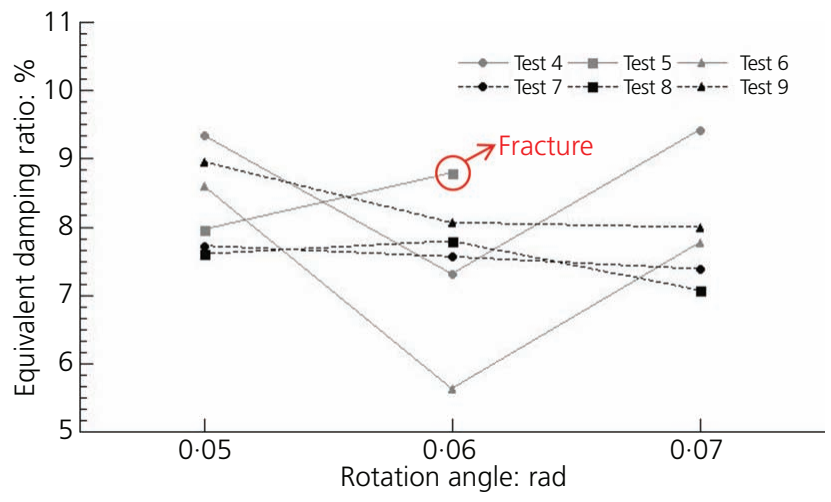

Figure 19. Change in equivalent damping ratios with roof weight

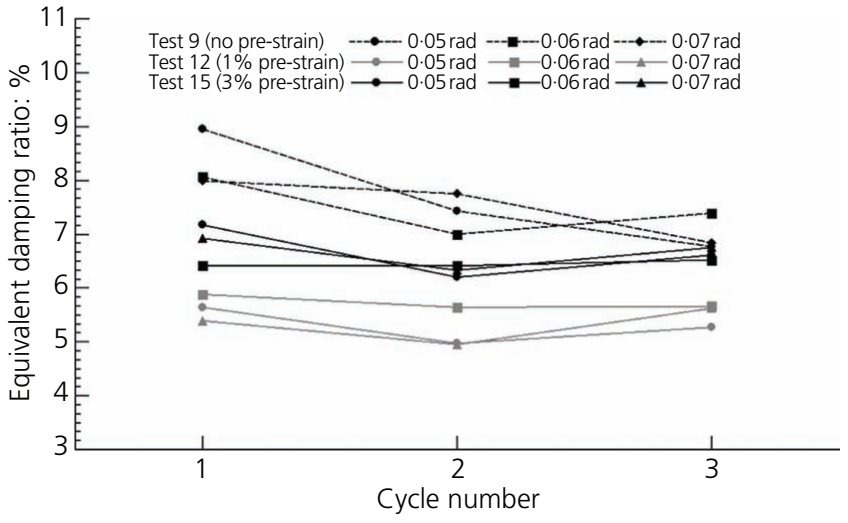

Figure 20. Change in equivalent damping ratios with the prestrain level of the super-elastic alloy

stiffness of the super-elastic alloy only under small displacements. The pre-strain of the super-elastic alloy allows the material to have initial super-elasticity and to dissipate a certain amount of energy, even under small displacements.

There are two possible reasons why a two-tiered Dou-Gong set gave a higher equivalent damping ratio in no-pre-strain loading cases than in pre-strain loading cases. The first is that pre-strain loading cases have a higher final stiffness than no-pre-strain cases. A higher moment is therefore needed to achieve the same rotation angle. Hence, $A_{\mathrm{e}}$, the maximum elastic strain energy in one loading cycle used to calculate the equivalent damping ratio, will be higher, and, thus, the final equivalent damping ratio will be smaller. The other reason may be that the top tier consists of several components, and the movements between these can also dissipate energy. However, the pre-strain of the upper tie connections bound the components tightly together and resisted any movement between them. Therefore, the pre-strain on the super-elastic alloy connection of the base Dou and the upper tier is the area that requires further investigation.

Like the no-pre-strain loading cases, the ultimate strength increases with the top loads applied on the Dou-Gong set in the pre-strain loading cases. The $3 \%$ pre-strain of the super-elastic alloy gave a slightly greater ultimate strength than the $1 \%$ prestrain. There are only two stages of stiffness in the Dou-Gong set with $1 \%$ pre-strain super-elastic alloy connections. Three stages of stiffness can be observed in the $3 \%$ pre-strain loading cases. The structure entered its third stage of stiffness when it was rotated more than $0.05 \mathrm{rad}$ because the super-elastic alloy transferred to its elastic deformation of detwinned martensite.

The equivalent damping ratio of 3\% pre-strain loading cases is always higher than $1 \%$ pre-strain loading cases (Figure 21). The equivalent damping ratio of the latter ranges from 5 to $7 \%$, and the former from 6 to $9 \%$. The equivalent damping ratio slightly decreases in the second and third loading cycles under $3 \%$ loading cases but not in the $1 \%$ loading cases. The equivalent 


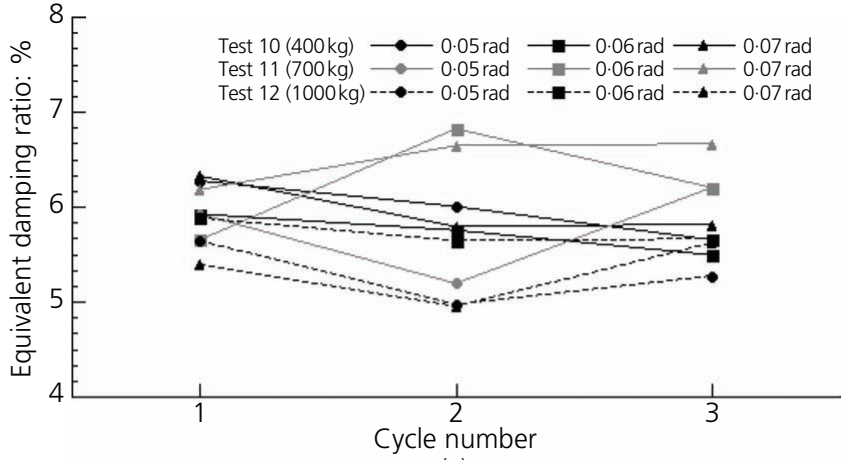

(a)

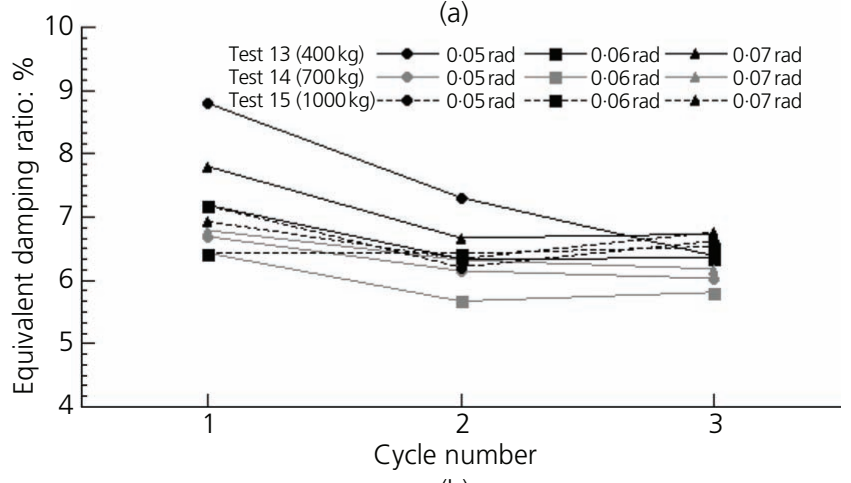

(b)

Figure 21. The effect of top loads on the equivalent damping ratio of the Dou-Gong with the super-elastic alloy pre-straining to (a) $1 \%$ and (b) $3 \%$ strain levels

damping ratio is also independent of the rotation angle of the Dou-Gong set with pre-strain super-elastic alloy bar connections.

\section{Conclusions}

This study used glulam to replicate a full-scale Dou-Gong system deriving from a historical timber building in Sichuan Province in China. High-strength steel and super-elastic alloy were used as substitutes for conventional wooden peg connections. Pushover tests were then conducted using a hydraulic jack. This technique addresses the needs of the cases which involve dismantling, repair and strengthening of those traditional timber structures with the Dou-Gong system. This technique is also reversible when the Dou-Gong system needs to be dismantled in the future. The following conclusions can therefore be drawn.

- The ultimate strength increased rapidly with the weight applied on the top of the structure when conventional wooden peg connections were used. This is because the wooden peg was pulled out from the hole without any damage and the lateral load generally overcame the weight on top. The P-delta effect had a higher impact when the weight on top was greater, resulting in lower stiffness of the Dou-Gong set.

- Both high-strength steel and super-elastic alloy give the DouGong system much higher ultimate stiffness than that would be provided by conventional wooden peg connections. The highstrength steel bar connections provided the Dou-Gong system with the highest equivalent damping ratio and stiffness but only in the first loading cycle. In the second and third loading cycles, the structure experienced a stage of near-zero stiffness before reaching ultimate strength due to the permanent deformation of the steel bar. The high-strength steel bar thus has a higher risk of fracture during repeated loading cycles.

n Four stages of stiffness were observed in the no-pre-strain loading cases of a Dou-Gong system with super-elastic alloy bar connections. The first two stages are regarded as the stiffness of the Dou-Gong system itself, and the latter two stages are the stiffness of the super-elastic alloy. The first two stages disappeared when pre-strain was applied to the superelastic alloy bars. The super-elastic alloy with 3\% pre-strain showed hysteresis loops with an area greater than that in nopre-strain loading cases; this means that the super-elastic alloy can dissipate more energy. The higher pre-strain level can thus provide the Dou-Gong structure with a higher equivalent damping ratio.

\section{Acknowledgements}

The authors would like to thank the International Copper Association for their financial support (TEK-1079) and Furukawa Techno Material for their sponsorship of the super-elastic alloy.

\section{REFERENCES}

Chang WS (2005) On Rotational Performance of Traditional Chuan-Dou Timber Joints in Taiwan. PhD thesis, National Cheng Kung University, Tainan, Taiwan.

Chang WS and Araki Y (2016) Use of shape-memory alloys in construction: a critical review. Proceedings of the Institution of Civil Engineers - Civil Engineering 169(2): 87-95, https://doi.org/10.1680/ jcien.15.00010.

Chang WS and Hsu MF (2005) Mechanical characteristics of traditional go-dou and stepped dovetail timber connections in Taiwan. Taiwan Journal of Forest Science 20(1): 61-71.

Chang WS and Hsu MF (2007) Rotational performance of traditional Nuki joints with gap II: the behavior of butted Nuki joint and its comparison with continuous Nuki joint. Journal of Wood Science 53(5): 401-407, https://doi.org/10.1007/s10086-007-0880-1.

Chang WS, Hsu MF and Komatsu K (2006) Rotational performance of traditional Nuki joints with gap I: theory and verification. Journal of Wood Science 52(1): 58-62, https://doi.org/10.1007/s10086-0050734-7.

Chang WS, Shanks J, Kitamori A and Komatsu K (2009) The structural behaviour of timber joints subjected to bi-axial bending. Earthquake Engineering and Structural Dynamics 38(6): 739-757, https://doi.org/ 10.1002/eqe.854.

Fang DP, Iwasaki S, Yu MH et al. (2001a) Ancient Chinese timber architecture - I: experimental study. Journal of Structural Engineering 127(11): 1348-1357, https://doi.org/10.1061/(ASCE)0733-9445(2001) 127:11(1348).

Fang DP, Iwasaki S, Yu MH et al. (2001b) Ancient Chinese timber architecture - II: dynamic characteristics. Journal of Structural Engineering 127(11): 1358-1364, https://doi.org/10.1061/(ASCE) 0733-445(2001)127:11(1358).

Fujita K, Sakamoto I, Ohashi Y et al. (2000) Static and dynamic loading tests of bracket complexes used in traditional timber structures in Japan. Proceedings of the 12th World Conference on Earthquake Engineering, Auckland, New Zealand, paper no. 0851.

Fujita K, Hanazato T and Sakamoto I (2004) Earthquake response monitoring and seismic performance of five storied timber pagoda. 
Engineering History and Heritage

Volume 172 Issue EH4
Static behaviour of a two-tiered Dou-

Gong system reinforced by super-elastic

alloy

Xie, Wang and Chang
Proceedings of the 13th World Conference on Earthquake Engineering, Vancouver, BC, Canada, paper no. 54.

Fujita K, Chiba K, Kawai N et al. (2008) Earthquake response analysis of traditional Japanese timber pagoda. Proceedings of the 10th World Conference on Timber Engineering, Miyazaki, Japan, pp. 1329-1336.

Hwang JK, Hong SG, Kim NH et al. (2008) The effect of friction joint and Gongpo (bracket set) as an energy dissipation in Korean traditional wooden structure. In Structural Analysis of Historic Construction (D'Ayala D and Fodde E (eds)). CRC Press, Boca Raton, FL, USA, pp. 861-866.

Priestley MJN, Seible F and Calvi GM (1996) Seismic Design and Retrofit of Bridges. Wiley, New York, NY, USA.

Suzuki Y and Maeno M (2006) Structural mechanism of traditional wooden frames by dynamic and static tests. Structural Control and Health Monitoring 13(1): 508-522, https://doi.org/10.1002/stc.153.

Tsuwa I, Koshihara M, Fujita K et al. (2008) A study on the size effect of bracket complexes used in traditional timber structures on the vibration characteristics. Proceedings of the 10th World Conference in Timber Engineering, Miyazaki, Japan, pp. 1344-1351.

Xie W, Araki Y and Chang WS (2018) Enhancing the seismic performance of historic timber buildings in Asia by applying super-elastic alloy to a
Chinese complex bracket system. International Journal of Architectural Heritage 12(4): 734-748, https://doi.org/10.1080/ 15583058.2018 .1442528

Xue J, Wu Z, Zhang F et al. (2015) Seismic damage evaluation model of Chinese ancient timber buildings. Advances in Structural Engineering 18(10): 1671-1683, https://doi.org/10.1260/1369-4332. 18.10.1671.

Yeo SY, Hsu MF, Komatsu K et al. (2016a) Shaking table test of the Taiwanese traditional Dieh-Dou timber frame. International Journal of Architectural Heritage 10(5): 539-557, https://doi.org/10.1080/ 15583058.2015.1009574.

Yeo SY, Komatsu K, Hsu MF et al. (2016b) Mechanical model for complex brackets system of the Taiwanese traditional Dieh-Dou timber structures. Advances in Structural Engineering 19(1): 65-85, https:// doi.org/10.1177/1369433215618269.

Yeo SY, Komatsu K, Hsu MF et al. (2018) Structural behavior of traditional Dieh-Dou timber main frame. International Journal of Architectural Heritage 12(4): 555-577, https://doi.org/10.1080/ 15583058.2018.1442518.

Yu MH, Oda Y, Fang DP et al. (2008) Advances in structural mechanics of Chinese ancient architectures. Frontiers of Structural and Civil Engineering 2(1): 1-25, https://doi.org/10.1007/s11709-008-0002-1.

\section{How can you contribute?}

To discuss this paper, please email up to 500 words to the editor at journals@ice.org.uk. Your contribution will be forwarded to the author(s) for a reply and, if considered appropriate by the editorial board, it will be published as discussion in a future issue of the journal.

Proceedings journals rely entirely on contributions from the civil engineering profession (and allied disciplines). Information about how to submit your paper online is available at www.icevirtuallibrary.com/page/authors, where you will also find detailed author guidelines. 